\title{
An Analysis of Factors Affecting Intention to Purchase Products and Services in Social Commerce
}

\author{
Mehdi Dashti ${ }^{1}$, Ali Sanayei ${ }^{2}$, Hossein Rezai Dolatabadi ${ }^{3}$ \& Mohammad Hossein Moshrefjavadi $^{3}$ \\ ${ }^{1}$ Ph.D. Candidate of Marketing Management, Dept. of Management, University of Isfahan, Isfahan, Iran \\ ${ }^{2}$ Professor of Marketing Management, Head of Management Research Institute, University of Isfahan, Isfahan, \\ Iran \\ ${ }^{3}$ Assistant Professor of Marketing Management, Faculty of Economic \& Official Sciences, University of Isfahan, \\ Isfahan, Iran \\ Correspondence: Ali Sanayei, Dept. of Management, University of Isfahan, Isfahan, Iran. E-mail: \\ a_sanayei@ase.ui.ac.ir
}

Received: June 20, 2016

doi:10.5539/mas.v10n12p98
Accepted: July 26, 2016

Online Published: August 3, 2016

URL: http://dx.doi.org/10.5539/mas.v10n12p98

\begin{abstract}
As a result of the popularity and growth of social networks, consumers often rely on recommendations and suggestions from online friends to make buying decisions. Through social commerce, people are driven from inefficient individual decisions toward collaborative decision-making with higher efficiency. In this paper, we study the factors that affect customer decisions on the purchase of recommended products and services in the context of social commerce. A total of 327 individuals on three popular social networks in Iran (i.e. Facebook, Cloob, and Telegram) were surveyed. Analysis of the results using the PLS-SEM approach revealed that: (1) Social commerce constructs has a positive effect on social support and relationship quality. (2) Perceived usefulness has a positive effect on relationship quality and intention to purchase. (3) social support has a positive effect on relationship quality and (4) relationship quality has a positive effect on intention to purchase.
\end{abstract}

Keywords: social commerce, social media, social commerce constructs, social support, intention to purchase

\section{Introduction}

Social commerce, also known as social business, refers to e-commerce activities conducted through social media. Thus, it may be considered as a branch of e-commerce which involves the use of social media to assist e-commerce transactions and other activities. It also supports social interaction and collaboration between the users (Liang et al., 2011). Therefore, social commerce is essentially a combination of e-commerce, e-marketing, support technologies, and social media content. In other words, social commerce is created by integrating e-commerce, e-marketing, and Web 2.0/social media. This integration is supported by a number of theories such as social capital, social psychology, consumer behavior, and online collaboration and has resulted in the development of many useful website and applications that create social commerce (Stephen \& Toubia, 2010). These websites and applications have the potential to be used as sources of information for products and services. Furthermore, customers are enabled to create content and share their information and experiences about products and services. This is extremely important and appealing to manufacturers and service providers since it influences the customer decision-making process (Hajli, 2014a). Therefore, this paper investigates the factors that affect the adoption of social commerce.

\section{Literature Review and Hypotheses Development}

\subsection{Social Commerce}

The development of Social Networks (SN) has resulted in a new paradigm of e-commerce known as social commerce. Although a standard definition of social commerce is lacking, generally, the concept refers to the provision of e-commerce activities and transactions through social media using Web 2.0 tools. Therefore, social commerce may be considered as a branch of e-commerce capable of supporting online social interactions of buying and selling products and services via SNs. In fact, social commerce is a combination of commerce and social activities (Hajli \& Sims, 2015). 
Social commerce supports social interactions to assist users in making decisions and obtaining products in online markets and communities. Given user participation as a key element, social commerce has a considerable impact on business and contributes to developing products, attaining market goals, and increasing sales (Stephen \& Toubia, 2010). It allows individuals to participate in activities pertaining to marketing, selling, comparing, and sharing products and services in online markets and communities through social media (Liang et al., 2011).

The new form of business created by social media helps customers make well-informed and accurate decisions. Additionally, customers are able to find products with lower prices (Kim et al., 2013). In fact, customers can access knowledge and experiences of others to find similar products with lower prices, thus gaining greater bargaining power through social commerce (Hajli, 2014a).

\subsection{Relationship Quality}

Relationship quality is an important concept in relationship marketing which refers to the closeness and strength of a relationship and plays a critical role in increasing customer loyalty. Also, it has been introduced as the evaluation of the strength of the relationship between the service provider and the customer and the final assessment of service providing user (Taylor et al., 2011).

Given the intangible nature of services, customers could be unwilling to trust the service provider. Relationship quality serves to minimize this lack of trust and enhance the relationship between the customer and the company, eventually leading to greater loyalty and profitability (Caceres \& Paparoidamis, 2007).

Relationship quality comprises three components: trust, satisfaction, and commitment (De wulf, et. al, 2001). A large body of literature exists on the individual impacts of these three components. For instance, Chen et al. (2009) demonstrated that trust plays a key role in following consumer-to-consumer websites. In another study, Teo et al. (2009) showed that trust and e-commerce success are related.

Many researchers have studied the impact of one or more components of relationship quality on purchase intention and behavior. For instance, Homburg et al. (2005) explored the impact of satisfaction on willingness to pay; and Verhoef et al. (2001) related commitment, satisfaction, and trust to consumer referrals and the number of services purchased. In this last study, all three components of relationship quality had an effect on referrals, but only the commitment factor significantly influenced the number of services purchased. Cronin and Taylor (1992), on the other hand, established that customer satisfaction was the most predictive of customers' intentions. Bloemer et al. (1998) established that different relationship quality components were important in different industries.

Therefore, the following is hypothesized:

H1: Relationship quality has a positive impact on user's intention to purchase.

\subsection{Social Support}

Social support is a multidimensional construct defined as perceptions or experiences of caring, responding, and supporting people in a social group (Taylor et al., 2004). House (1981) identified four types of social support: emotional, instrumental, informational, and appraisal. Since the creation of content and relationships are the main features of social commerce, social support in social commerce revolves around informational and emotional support. Informational support refers to cognitive feelings arising from the content of recommendations, advice, or the knowledge that may prove beneficial in solving problems (Liang et al., 2011). Emotional support, on the other hand, pertains to experiences that are affected by emotional concerns including caring, understanding, and empathy (Coulson et al., 2011).

Stronger social support results in increased mutual understanding and greater warmth in the relationship. In other words, it can serve to fulfill the customers' needs, motivating them to interact with each other. As interactions and support information develop, higher levels of customer satisfaction and warmer relationships are observed. In previous studies, social support has been shown to improve relationship quality (Rishka et al., 2013). Therefore, we predict that greater social support leads to close and warm relationships with higher quality. It is hypothesized that:

H2: Social support has a positive impact on relationship quality.

\subsection{Social Commerce Constructs}

Refers to tools derived from social commerce such as online forums, communities, ratings, reviews, and recommendations (Hajli, 2013). These tools generate textual information capable of influencing customer buying behaviors (Hajli, 2015). Individuals use them to add value to their information. Also, they can be used to share information, express opinions and emotions regarding current or future products and services. Social commerce 
websites, commercial websites and social networks can leverage one or several such tools at a time. Depending on their nature, the tools may or may not result in an increased sense of care, interest, and (social) support among the members of a group (Hajli and Sims, 2015). Moreover, commitment, satisfaction, and trust among group members are likely to be influenced by such feelings (Hajli, 2014).

Based on the preceding explanations about social commerce constructs the following are postulated:

H3: Social commerce constructs have a positive effect on social support.

H4: Social commerce constructs have a positive effect on relationship quality.

\subsection{Perceived Usefulness}

Perceived usefulness is a main component of the Technology Acceptance Model (TAM) which states that and individual's decision to adopt a technology is dependent on two behavioral beliefs: perceived usefulness and perceived ease of use. Perceived usefulness is defined as the subjective expectation of the user regarding the extent to which a particular technology will enhance his/her performance (Davis, 1989).

Moreover, the model suggests that perceived usefulness impacts behavioral intention.

Many recearchs believe that perceived usefulness affects users' intentions to use e-commerce (Gefen and Straub, 2000). This construct is applied here in social commerce as well.

Han and Windsor (2011) examine the user's willingness to pay on SNSs. They used the new construct "perceived value of online connection" instead of perceived usefulness. They found a significant positive effect of the user's perceived value of online connection on their willingness to pay other members of SNSs (Han and Windsor, 2011).

Useful and straightforward information on a web site increases the level of online trust and consequently increases intention to use a system (Yu-Hui \& Barnes, 2007). Research shows the more useful functions that a web site provides, such as good information and content, the more trust a customer will have in it (Yu-Hui and Barnes,

2007). In addition, some research shows that trust in e-commerce has a positive impact on satisfaction and commitment (Roca et al., 2011). Thus we can postulate that:

H5: Perceived usefulness has a positive impact on relationship quality.

H6: Perceived usefulness has a positive impact on user intention to buy.

\section{Conceptual Model}

Based the review of literature in the previous section, the conceptual model of the study is illustrated in Figure 1.

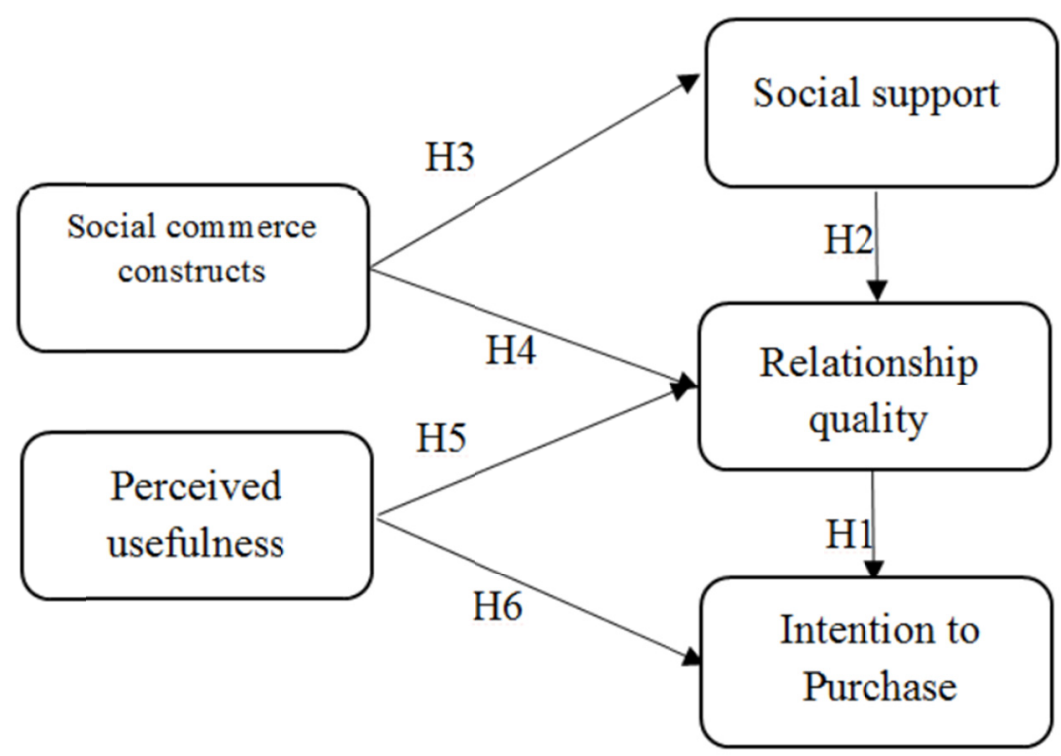

Figure 1. Research Model 


\section{Method}

\subsection{Instrument}

A total of five constructs are considered in this study: social commerce constructs, perceived usefulness, śsocial support, relationship quality and intention to purchase on social commerce. A questionnaire was used to measure the constructs. Answers were given on a five-point Likert scale of 1 (completely disagree) to 5 (completely agree).

\subsection{Data Collection}

The survey was conducted on the users of two popular non-Iranian SNs, namely Facebook and Telegram, as well as an Iranian SN called Cloob (www.cloob.com). In addition to their popularity, Facebook and Telegram were selected to represent web-based and application-based SNs, respectively. An online version of the questionnaire was used. In doing so, subsequent to designing the online survey, an access link was shared in groups and forums on the aforementioned SNs. After dropping the incomplete responses, a total of 327 responses were used for analysis purposes. Demographic characteristics of the respondents are shown in Table 1.

Table 1. Demographic Information

\begin{tabular}{lll}
\hline Demographics & Category & Percentage \\
\hline Gender & Male & 52.5 \\
Age & Female & 47.5 \\
& 19 or Younger & 15.87 \\
& $20-29$ & 52.17 \\
Education & $30-39$ & 29.11 \\
& 40 or Older & 2.85 \\
& High school or below & 17.05 \\
Frequency of online shopping & Associate and Bachelor & 44.55 \\
(Per month) & MA or its equivalent & 33.29 \\
& Doctoral or above & 5.11 \\
& Less than 1 time & 35.29 \\
& $1-2$ times & 31.33 \\
& $3-4$ times & 24.15 \\
& More than 4 times & 9.23 \\
\hline
\end{tabular}

In this paper, the Structural Equation Modelling (SEM) approach and Partial Least Squares (PLS) are used for evaluating the hypotheses and confirming reliability and validity.

\section{Data Analysis and Findings}

\subsection{Measurement Model}

\subsubsection{Reliability}

Among the various methods for testing reliability, Composite Reliability (CR) is recommended for PLS (Raykov, 1998). Values exceeding the threshold of 0.7 indicate acceptable CR (McLure Wasko and Faraj, 2005). As evident in Table 2, all constructs meet the threshold and are thus acceptable. Moreover, Cronbach's alpha for all constructs is larger than 0.7 , demonstrating sufficient reliability.

\subsubsection{Validity}

To ensure content validity, measurements for all constructs of the study are obtained from relevant literature on e-commerce and social commerce. The constructs, as well as the pertinent items and references, can be seen in Table 2.

Another type of validity i.e. construct validity was examined through convergent and discriminant validity. Table 2 presents assessment results for the former. As shown, Average Variance Extracted (AVE) values are larger than 0.5 for all constructs. Thus, the measurement model provides adequate convergent validity. 
Table 2. Sources of constructs, reliability and validity

\begin{tabular}{|c|c|c|c|c|c|}
\hline Constructs & Items & Loadings & CR & AVE & Cronbach's alpha \\
\hline Social Commerce Constructs & SCC1 & 0.795 & 0.859 & 0.591 & 0.808 \\
\hline Adapted from Hajli $(2014 a, 2014 b) ;$ Hajli and Sims, & $\mathrm{SCC} 2$ & 0.794 & & & \\
\hline$(2015)$ & SCC 3 & 0.801 & & & \\
\hline & $\mathrm{SCC} 4$ & 0.812 & & & \\
\hline \multicolumn{6}{|l|}{ Perceived Usefulness } \\
\hline \multirow[t]{2}{*}{ Davis, (1989); Gefen and Straub, (2000). } & PUS1 & 0.727 & 0.744 & 0.691 & 0.793 \\
\hline & PUS2 & 0.802 & & & \\
\hline \multirow{3}{*}{$\begin{array}{l}\text { Social Support } \\
\text { Adapted from Liang et. al, (2011); Hajli } \\
(2014 a, 2014 b, 2015)\end{array}$} & & & & & \\
\hline & SS1 & 0.811 & 0.766 & 0.711 & 0.885 \\
\hline & $\mathrm{SS} 2$ & 0.757 & & & \\
\hline Relationship Quality & SS3 & 0.721 & & & \\
\hline \multirow{4}{*}{$\begin{array}{l}\text { Adapted from Garbarino and Johnson, (1999); Liang et. } \\
\text { al, (2011); Hajli (2014a) }\end{array}$} & SS4 & 0.718 & & & \\
\hline & RQ1 & 0.792 & 0.875 & 0.714 & 0.888 \\
\hline & RQ2 & 0.813 & & & \\
\hline & RQ3 & 0.873 & & & \\
\hline Intention to purchase on social commerce & RQ4 & 0.818 & & & \\
\hline Adapted from Liang et. al, (2011); Hajli (2014a); Zhang & RQ5 & 0.831 & & & \\
\hline \multirow[t]{4}{*}{ et. al, (2014) } & RQ6 & 0.852 & & & \\
\hline & IB1 & 0.765 & 0.821 & 0.612 & 0.814 \\
\hline & IB2 & 0.821 & & & \\
\hline & IB3 & 0.818 & & & \\
\hline
\end{tabular}

With respect to discriminant validity, the square root of AVE values for each construct should be greater than the correlations involving the construct (Fornell and Larcker, 1981). According to Table 3, all constructs meet this criterion and discriminant validity can be established.

Table 3. Results of discriminant validity testing

\begin{tabular}{llllll}
\hline & SS & ITP & PUS & RQ & SCC \\
\hline SS & $\mathbf{0 . 8 4 3}$ & & & & \\
ITP & 0.412 & $\mathbf{0 . 7 8 2}$ & & & \\
PUS & 0.491 & 0.512 & $\mathbf{0 . 8 3 1}$ & & \\
RQ & 0.308 & 0.304 & 0.315 & $\mathbf{0 . 8 4 5}$ & \\
SCC & 0.357 & 0.401 & 0.319 & 0.404 & $\mathbf{0 . 7 6 9}$ \\
\hline
\end{tabular}

\subsection{Measurement Model}

The estimation results from SmartPLS software are shown in Figure 2. According to the results, all the paths among constructsare positive and significant at the 0.05 level. The model validity is assessed by $\mathrm{R}$ square value and the structural paths (Chwelos et al., 2001). The results of the $\mathrm{R}$ square indicate that almost $36 \%$ of the variance in the intention to purchase was accounted for by relationship quality and perceived usefulness. It means intention to purchase was, as hypothesized, affected by relationship quality and perceived usefulness. The result also shows that $28 \%$ of the variance relationship quality was accounted for by social commerce construct, perceived usefulness and social support. The $\mathrm{R}$ square for social support means that $42 \%$ of the variance in this construct was accounted for by Social commerce constructs. Hence, the result of R square shows a satisfactory level of explanation.

According to the results of path coefficients relationship quality $(0.363)$ and perceive usefulness $(0.291)$ both have significant effects on social commerce. Hence H1 and H6 are supported. Also social support (0.412), social 
commerce construct (0.324) and perceived usefulness $(0.312)$ have significant effects on relationship quality hence H2, H4 and H5 supported. Finally, social commerce constructs accounts for 45.1 percent of the variance in social support and it means $\mathrm{H} 3$ supported.

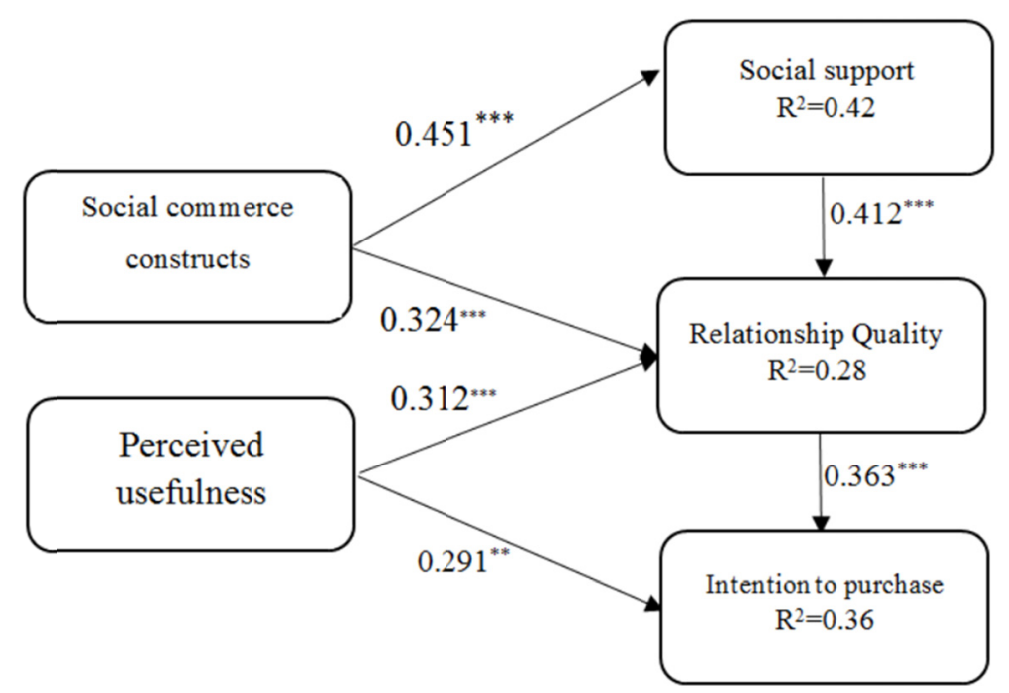

Figure 2. Results of the PLS analysis. ${ }^{* *} \mathrm{p}<0.01,{ }^{* * *} \mathrm{p}<0.001$

\section{Discussion and Conclusion}

This paper seeks to analyze the factors that influence customers' intentions to purchase products and services in the context of social commerce while focusing on the future of e-commerce and predicting consumer behaviors in social commerce environments. The predictions can prepare companies to develop strategies for social media as well as adoption and advancement of new technologies. Social media strategies are pivotal to attracting consumers in a platform wherein they are increasingly connected through social media. Thus, the factors that influence user intentions to purchase products and services in social commerce must be understood. Through this insight, it is possible to identify the causes of social commerce popularity and significantly help online marketing strategies.

Due to the popularity of social media, social relationships between consumers on the internet have given rise to the new concept of social commerce. This paper employs a number of theories from several disciplines to study consumer behavior in the context of social commerce: theory of social support from social psychology; relationship quality from marketing; social media vision and social commerce constructs from information systems; and satisfaction with the choice of social medium. The proposed model suggests that the constructs of social commerce, the ability to enhance relationship quality, and the perception of usefulness result in the behavioral intention to make purchases in a social commerce setting. Our findings reveal that social commerce constructs have a significant positive impact on social support and relationship quality (both directly and via social support). This means that by integrating socialization features into commercial websites, users are given a sense of support and community which can directly and indirectly (via social support) improve trust, satisfaction, commitment, and naturally relationship quality. Furthermore, relationship quality which is measured using the components of commitment and satisfaction has a mediating role in increasing the tendency to purchase in social commerce. In the context of e-commerce, where transactions are carried out via the internet, trust is much more significant; it leads to satisfaction and ultimately commitment, loyalty, and buying in social commerce. The results indicated that perceived usefulness impacts tendency to purchase in social commerce both directly and indirectly through relationship quality. This implies that perceptions of the usefulness of social commerce increase trust, commitment, and satisfaction among consumers, which in turn leads to a higher tendency to make purchase in social commerce. Moreover, if social commerce is perceived as a useful and effective tool for buying services and products, it may directly influence consumer purchase decisions.

The findings of this study have important practical implications. Firstly, by joining online communities, individuals begin to create information content on products and services. This information can affect relationship quality and lead to higher/lower loyalty among customers. In this regard, social commerce constructs play a key 
role. Thus, firms can leverage social commerce tools (e.g. forums) on social commerce websites or integrate these tools into their existing e-commerce platforms to create an environment wherein customers are able to discuss their products and services. Thus, a social environment is created and relationship quality is enhanced resulting in customer loyalty and higher company value. Through social support, such circumstances become particularly beneficial to the success of product or brand development efforts.

Secondly, social media owners or business managers must gain benefits by understanding why consumers use these websites. For instance, by learning that users are interested in entertainment and searching SNs and implementing such features, one can attract a greater number of consumers.

Thirdly, by learning about the consumers' true opinions and intentions regarding social commerce, business managers will be able to eliminate weaknesses, fulfill consumer needs, and create a superior shopping experience. Furthermore, business managers can leverage social media to contact potential consumers and remain in communication with existing ones.

\section{References}

Bloemer, J., De Ruyter, K., \& Wetzels, M. (1998). Linking perceived quality and service loyalty: A multi-dimensional perspective. European Journal of Marketing, 33(11), 1082-1106. http://dx.doi.org/10.1108/03090569910292285

Caceres, R. C., \& Paparoidamis, N. G. (2007). Service quality, relationship satisfaction, trust, commitment and business-to-business loyalty. European Journal of Marketing, 41(7-8), 836-867. http://dx.doi.org/10.1108/03090560710752429

Chen, J., Zhang, C., \& Xu, Y. (2009). The role of mutual trust in building members' loyalty to a C2C platform provider. International Journal of Electronic Commerce, 14(1), 147-171. http://dx.doi.org/10.2753/JEC1086-4415140105

Chwelos, P., Benbasat, I., \& Dexter, A. S. (2001). Research report: Empirical test of an EDI adoption model. Information Systems Research, 12(3), 304-321. http://dx.doi.org/10.1287/isre.12.3.304.9708

Coulson, N. S. (2005). Receiving social support online: an analysis of a computer-mediated support group for individuals living with irritable bowel syndrome. Cyber Psychology \& Behaviour, 8, 580-584. http://dx.doi.org/10.1089/cpb.2005.8.580.

Cronin, J. J., \& Taylor, S. A. (1992). Measuring service quality: A reexamination and extension. Journal of Marketing, 56(3), 55-68. http://dx.doi.org/10.2307/1252296

Davis, F. D. (1989), Perceived usefulness, perceived ease of use, and user acceptance of information technology. MIS Quarterly, 13, 319-340. http://dx.doi.org/10.2307/249008

De Wulf, K., Odekerken-Schröder, G., \& Lacobucci, D. (2001). Investments in consumer relationships: A cross-country and cross-industry exploration. Journal of Marketing, 65(4), 33-51. http://dx.doi.org/10.1509/jmkg.65.4.33.18386

Fornell, C., \& Larcker, D. F. (1981). Evaluating structural equation models with unobservable variables and measurement error. Journal of Marketing Research, 18, 39-50. http://dx.doi.org/10.2307/3151312

Garbarino, E., \& Johnson, M. S. (1999). The different roles of satisfaction, trust, and commitment in customer relationships. Journal of Marketing, 63(4), 70-87. http://dx.doi.org/10.2307/1251946

Gefen, D., \& Straub, D. (2000). The relative importance of perceived ease of use in IS adoption: a study of e-commerce adoption. Journal of the Association for Information Systems, 1(8), 1-28.

Hajli, N. (2013). A research framework for social commerce adoption. Information Management \& Computer Security, 21(3), 144-154. http://dx.doi.org/10.1108/IMCS-04-2012-0024

Hajli, N. (2014a). The role of social support on relationship quality and social commerce. Technological Forecasting and Social Change, 87, 17-27. http://dx.doi.org/10.1016/j.techfore.2014.05.012

Hajli, N. (2014b). A study of the impact of social media on consumers. International Journal of Market Research, 56(3), 388-404. http://dx.doi.org/10.2501/IJMR-2014-025\#sthash.UyFXyGfJ.dpuf

Hajli, N., \& Sims, J., (2015). Social commerce: The transfer of power from sellers to buyers. Technological Forecasting and Social Change, 94, 350-358. http://dx.doi.org/10.1016/j.techfore.2015.01.012

Han, B. O., \& Windsor, J. (2011). User's willingness to pay on social network sites. Journal of Computer Information Systems, 51, 31-40. http://dx.doi.org/10.1080/08874417.2011.11645499 
Homburg, C., Koschate, N., \& Hoyer, W. D. (2005). Do satisfied customers really pay more? A study of the relationship between customer satisfaction and willingness to pay. Journal of Marketing, 69(2), 84-96. http://dx.doi.org/10.1509/jmkg.69.2.84.60760

House, J. S. (1981). Work stress and social support. Reading, MA: Addison-Wesley.

Kim, S., \& Park, H. (2013). Effects of various characteristics of social commerce (s-commerce) on consumers' trust and trust performance. International Journal of Information Management, 33(2), 318-332. http://dx.doi.org/10.1016/j.ijinfomgt.2012.11.006

Liang, T. P., Ho, Y. T., Li, Y. W., \& Turban, E. (2011). What drives social commerce: the role of social support and relationship quality. International Journal of Electronic Commerce Article, 16(2), 69-90. http://dx.doi.org/10.2753/JEC1086-4415160204

McClure, Wasko, M., \& Faraj, S. (2005). Why should I share? Examining social capital and knowledge contribution in electronic networks of practice. MIS Quarterly, 29(1), 35-57. http://dx.doi.org/10.2307/25148667

Raykov, T. (1998). Coefficient alpha and composite reliability with interrelated nonhomogeneous items. Applied Psychological Measurement, 22(4), 375-385. http://dx.doi.org/10.1177/014662169802200407

Rishika, R., Kumar, A., Janakiraman, R., \& Bezawada, R. (2013). The effect of customers' social media participation on customer visit frequency and profitability: an empirical investigation. Information systems research, 24(1), 108-127. http://dx.doi.org/10.1287/isre.1120.0460

Roca, J. C., Garci'a, J. J., \& de Lavega, J. J. (2009). The importance of perceived trust, security and privacy in online trading systems. Information Management \& Computer Security, 17, 96-113. http://dx.doi.org/10.1108/09685220910963983

Stephen, A. T., \& Toubia, O. (2010). Deriving Value from Social Commerce Networks. Journal of Marketing Research, 47(2), 215-228. http://dx.doi.org/10.1509/jmkr.47.2.215

Taylor, S. E., Sherman, D. K., Kim, H. S., Jarcho, J., Takagi, K., \& Dunagan, M. S. (2004). Culture and social support: Who seeks it and why? Journal of Personality and Social Psychology, 87, 354-362. http://dx.doi.org/10.1037/0022-3514.87.3.354.354

Teo, T. S., Srivastava, S. C., \& Jiang, L. (2008). Trust and electronic government success: An empirical study. Journal of Management Information Systems, 25(3), 99-132. http://dx.doi.org/10.2753/MIS0742-1222250303

Verhoef, P. C., Franses, P. H., \& Hoekstra, J. C. (2001). The impact of satisfaction and payment equity on cross-buying: A dynamic model for multi-service provider. Journal of Retailing, 77(3), 359-378. http://dx.doi.org/10.1300/J366v05n02_06

Yu-Hui, C., \& Barnes, S (2007), Initial trust and online buyer behavior. Industrial Management Data Systems, 107(1), 21-36. http://dx.doi.org/10.1108/02635570710719034

Zhang, H., Lu, Y., Gupta, S., \& Zhao, L. (2014). What motivates customers to participate in social commerce? The impact of technological environments and virtual customer experiences. Information \& Management, 51, 1017-1029. http://dx.doi.org/10.1016/j.im.2014.07.005

\section{Appendix A}

\section{Questionnaire Items}

Social Commerce Constructs

SCC1 I will ask my friends on forums and communities to provide me with their suggestions before I go shopping.

SCC2 I am willing to recommend a product that is worth buying to my friends on the Cloob (Facebook)(Telegram)

SCC3 I am willing to share my own shopping experience with my friends on forums and communities or through ratings and reviews.

SCC4 I would like to use people's online recommendations to buy a product.

Perceived Usefulness 
PUS1 Cloob (Facebook)(Telegram) enables me to discover new products and get shopping idea more quickly.

PUS2 Cloob (Facebook)(Telegram) increases my productivity in discovering products and getting shopping ideas.

\section{Social Support}

SS1 When faced with difficulties, some people on the Cloob (Facebook)(Telegram) are on my side with Me.

SS2 When faced with difficulties, some people on the Cloob (Facebook)(Telegram) listened to me talk about my private feelings.

SS3 On Cloob (Facebook)(Telegram) some people would offer suggestions when I need help

SS4 When faced with difficulties, some people on the Cloob (Facebook)(Telegram) would help me discover the cause and provide me with suggestions.

Relationship Quality

RQ1 I am proud to belong to the membership of Cloob (Facebook)(Telegram).

RQ2 I feel a sense of belonging to Cloob (Facebook)(Telegram).

RQ3 I am happy with Cloob (Facebook)(Telegram).

RQ4 I am satisfied with using Cloob (Facebook)(Telegram).

RQ5 The performance of Cloob (Facebook)(Telegram) always meets my expectations.

RQ6 Cloob (Facebook)(Telegram) is a reliable social networking site.

Intention to purchase on social commerce

ITP1 I am likely to pay for fees to have speed dating on social SNSs.

ITP2 I am likely to pay for the membership if SNSs charging fees.

ITP3 I am very likely to buy books from SNSs

\section{Copyrights}

Copyright for this article is retained by the author(s), with first publication rights granted to the journal.

This is an open-access article distributed under the terms and conditions of the Creative Commons Attribution license (http://creativecommons.org/licenses/by/3.0/). 